\title{
Evaluation of Bull Semen Quality and Sperm DNA Integrity during Cryopreservation with Different Cryoprotectants
}

\author{
Muhammad Amjad Khan', Sarwat Jahan², Asmara Imtiaz ${ }^{1}$, Naureen Naeem ${ }^{1, *}$ \\ ${ }^{1}$ Department of Biology, Lahore Garrison University, Lahore, Pakistan \\ ${ }^{2}$ Department of Animal Sciences Quaid-i-Azam University, Islamabad, Pakistan
}

Received October 28, 2019; Revised December 20, 2019; Acceptance December 25,2019

Copyright $\bigcirc 2019$ by authors, all rights reserved. Authors agree that this article remains permanently open access under the terms of the Creative Commons Attribution License 4.0 International License

\begin{abstract}
The fertility rate in dairy cattle with cryopreserved semen significantly depends on the reduction of the toxic effects on the sperms induced during cryopreservation. DNA integrity in sperm is vital for the precise transmission of genetic information and therefore the production of high yielders and maintenance of good health in future generations. The reliable and consistent assessment of sperm motility can be succeeded by Computer Assisted Semen Analyzer (CASA). Ten ejaculates were collected from Frisian bulls kept at Centre of excellence for bovine genetics (CEBG) Renala Khurd District Okara. The deleterious effects of three cryoprotectants glycerol, dimethylsulfoxide (DMSO) and ethylene glycol as a constituent of tris-egg yolk-citrate extender were compared on diluted post thawed cryopreserved Frisian bull semen. The quality of semen in terms of viability/motility/progressive velocity was determined with computerized external real image optical system (CEROS) and sperm DNA fragmentation was quantified with comet assay using single cell gel electrophoresis (SCGE) technique. Glycerol was the least followed by DMSO and ethylene glycol was the most toxic cryoprotectant both for semen quality and sperm DNA fragmentation. The present study suggests that sperm DNA fragmentation is an associated feature of semen cryopreservation resulting into cell death (non-motile sperms) and glycerol as a cryoprotectant constituent of tris-egg yolk citrate extender offers a better protection for storage of cryopreserved Frisian bull semen in liquid nitrogen.
\end{abstract}

Keywords Bull Semen Quality, CASA, Comet assay, Cryopreservation, Cryoprotectants, DNA Integrity

\section{Introduction}

The fertility rate in animal production mainly depends upon the quality of semen. In dairy cattle, the extensive usage of artificial insemination (AI) has ensued in increased selection intensity, resultantly achieving enhanced productivity (Naveen et al., 2014). Deep freezing of semen in liquid nitrogen has paved the way to preserve allele variation and genetic material of rare and likely to be extinct wildlife species (Lemma, 2010). The plasma membrane of sperm is damaged when exposed to freezing process and thawing. This leads to availability of less live / motile sperms and is the major hurdle to utilize cryopreserved semen of many species (Hammerstedt et al., 1990). Bull semen is cryopreserved using standard extenders that usually consist of regular or skim milk or a tris solution added with egg yolk (Hinsch et al., 1997).During cryopreservation sperm DNA damage may result because ofoxidative stress (Bayejidet al., 2015). Cryoprotective agents (CPAs) at specific concentration are required that entersperm cell membrane to increase membrane fluidity. This results in partial dehydration of cell, low freezing point and reduced number and size of intracellular ice crystals (Swain and Smith, 2010). The fertility rate in sows with cryopreserved semen is increased by supplementing cryopreservation media with reduced glutathione (Estrada et al., 2014). Sex sorted semen can also be used to further improve the results of AI (Thomas et al., 2014, Karakaya et al., 2014). The reliable and consistent assessment of sperm motility can be succeeded by Computer Assisted Semen Analyzer (CASA).For analysis of sperm quality, CASA is the most independent and inclusive available gadget which aids rapid assessment of motility percentage, velocity and other descriptions. It can be successfully used for both fresh and post thawed semen analysis. Assessment of motility parameters through 
CASA separately and in combination with a semi defined extender using Computerized External Real Optical System (CEROS) sperm analyzer 12.1 (Hamilton Thorne Biosciences, USA) has been established (Albrecht et al., 2004). It is generally understood that the fittest sperm with intact DNA will fertilize the ovum however sperm with damaged DNA may also achieve fertilization but this is proposed to result in compromised pregnancy consequences (Morris et al., 2002). Pregnancy percentage correlation with motility has been shown in bovine spermatozoa (Correa et al., 1997) and with progressive motility in the horse stallion (Neild et al., 1999). Sperm DNA disintegration can be a consequence of the cryopreservation process and thawing (Steele et al., 2000, Erma and Martin, 2015). There are different approaches in practice to evaluate the DNA disintegration, such as the orthodox agarose gel electrophoresis but a more current technique is single cell gel electrophoresis (Anderson and Laubenthal, 2013, Soudabeh et al., 2016). This technique was first presented in 1984 and has developed intoa renowned method toidentify DNA fragmentations in a range of cell types, including sperm cells (Steele et al., 2000).Commonly this assay is termed as Comet assay, since broken and intact DNA as a whole looks like a comet and is a simple, quick, optical and sensitive technique for detecting primary DNA damage at the single cell level (Singh et al., 1989). For detection of DNA damage during liquid nitrogen.In domestic farm animals, the comet assay has been applied on boar semen to detect DNA damage during liquid nitrogen storage (Fraser and Strzezek, 2007), to detect metal induced DNA damage in fish (Kousar and Javed, 2015) and to detect nanoparticle induced genotoxicity (Karlsson et al., 2015). Several procedures have been suggested to reveal sperm DNA aberrations and DNA staining by acridine orange. Based on the respective colors and fluorescence, single and double stranded DNA breaks can be distinguished. (Hammadeh et al., 1999). For the expansion and preservation of a progeny, study on sperm DNA fragmentation may give complementary information to improve the cryopreservation practices (Phil and Peter, 2016).The characteristics of comets and quantification of sperm DNA damage have been given less attention for research studies in the past

The objective of present study was to evaluate the proficiency of Glycerol, DMSO and Ethylene glycolas CPA of tris egg yolk citrate extender by assessing semen quality descent / sperm DNA fragmentation and to find out any correlation between these two phenomenon.

\section{Materials and Methods}

Ten 4-5 years age healthy Frisian bulls, weighing $525-600 \mathrm{~kg}$ with more than $70 \%$ motility of individual fresh semen sample were selected from Centre of Excellence for Bovine Genetics (CEBG) Renala Khurd,
District Okara. The semen was collected from all the bulls at one day using artificial vagina.

Design: The control group included fresh semen samples at $37^{\circ} \mathrm{C}$ of ten ejaculates. Experimental group A included cryopreserved at $-196^{\circ} \mathrm{C}$ semen samples of ten ejaculates diluted in tris- egg yolk- citrate extender containing glycerol as CPA, group B containing DMSO as CPA and group C containing ethylene glycol as CPA. The samples of control group were processed for evaluation of semen quality viz motility/viability and sperm DNA fragmentation after $30 \mathrm{~min}$ of semen collection using CEROS and Comet Assay respectively. The cryopreserved samples were evaluated after 90 days storage. Three samples of each ejaculate were processed for semen evaluation and comet assay, thus making a total of 240 samples. The quality of semen was evaluated in the laboratory of CEBG Renala / Biological research lab Lahore Garrison University whereas the samples for comet assay were processed in Reproductive Physiology Laboratory, Department of Animal Sciences Quaid-i-Azam University Islamabad.

Semen processing: Semen was divided into four equal fractions; the first one was not diluted with any extender and was used to evaluate semen quality and DNA damage as control samples, the remaining were diluted in extender A, B and C respectively for cryopreservation and subsequent examination as experimental samples. The dilution was made keeping in view that $0.5 \mathrm{ml}$ of semen straw contained $0.5 \mathrm{M}$ sperm cells and accordingly $100 \mathrm{ul}$ contained 100,000 sperm cells. The mixture was cooled gradually to $5^{\circ} \mathrm{C}$. White, green, yellow and blue straws were used for control, A, B and C groups respectively. The straws were frozen using computerized programmable freezer that decreased temperature from $4^{\circ} \mathrm{C}$ to $-140^{\circ} \mathrm{C}$ at the rate of $10^{\circ} \mathrm{C} / \mathrm{min}$ and finally placed in liquid nitrogen tank for storage. (Fraser and Strzezek, 2007).

Evaluation of Semen Quality: Computerized External Real Optical System CEROS, a CASA technique was used to evaluate the quality semen samples. The motility parameters i.e., percentage of motile, static, slow $(<10 \mu \mathrm{m} / \mathrm{sec})$, moderate $(<25 \mu \mathrm{m} / \mathrm{sec})$, rapid $(>25 \mu \mathrm{m} / \mathrm{sec})$ sperms and progressive velocity i.e., velocity straight line (VSL) were recorded with the CEROS sperm analyzer 12.1, Hamilton Thorne Biosciences, Inc., Beverly, MA, USA) on 100,000 spermatozoa. (Tardif et al., 1997)

Evaluation of sperm DNA integrity: For Comet Assay three agarose coated slides containing $100 \mu \mathrm{L}$ of semen for each sample were prepared making total of 30 slides for each group. These were placed in lysing solution for 48 hours and then dipped in lysing solution that contained protienase $\mathrm{K}(10 \mu \mathrm{l} / 100 \mathrm{ml}$ of lysing solution) for 2 hours at $37^{\circ} \mathrm{C}$ in dark. Unwinding of DNA was achieved using Tris, Boric acid, EDTA (TBE) buffer. Eltrophoresis was done at 25 volts, $300 \mathrm{~mA}$ and for $20 \mathrm{~min}$. Each time freshly stained slides with $1 \%$ acridine orange (for $5 \mathrm{~min}$ in dark room) were examined for comet characteristic analysis under 
Optiphot-2 Nikon microscope (epifluorescence) Plan Fluor, Nikon, UK, equipped with filters (green DM430and blue DM510) and having an attachment to Cannon Digital Camera. For morphometric analysis 200 cells were counted from four fields of each slide counting the intact DNAs and comets. Comets were scored using TRITEK software. (Mariola et al., 2008)

\section{Statistical Analysis}

Comparison of the mean \pm SEM values between control and experimental groups performed through ANOVA. Mean \pm SEM values within the groups were analyzed and compared by Tukey's post hoc test. Graph Pad Prism version 5.00 was used to analyze the data. (Morris et al., 2002)

\section{Results}

Motility: A highly significant decrease $(\mathrm{P}<0.0001)$ in percentage of motile sperms was noticed in all three experimental groups and the same was observed when comparison was made in between experimental groups. Correspondingly there was highly significant $(\mathrm{P}<0.0001)$ increase in the percentage of static sperms in experimental groups as compared in control group. There was no significant increase or decrease in slow moving sperms. There was a significant $(\mathrm{P}<0.05)$ increase in slow moving sperms in group $\mathrm{C}$ (cryopreserved with ethylene glycol) when compared with control. No significant decrease or increase in percentage of moderately moving sperms was noticed in all groups. Comparison of percentage rapidly moving sperms between control and experimental showed a highly significant $(\mathrm{P}<0.0001)$ decrease in all three experimental groups (table 1).

Progressive velocity: Significant decrease $(\mathrm{P}<0.05)$ in progressive velocity of sperms in experimental group $\mathrm{A}$ was observed. There was highly significant decrease $(\mathrm{P}<0.0001)$ in progressive velocity between control group and group $\mathrm{B}$ and group $\mathrm{C}$ (table 2 ).

Sperm DNA fragmentation: The mean extent of DNA damage in individual sperm cell was $17.92 \%$ in control group, $22.05 \%$ in group A, $24.86 \% \mathrm{~B}$ and $32.23 \%$ in $\mathrm{C}$. Comparison of control group with experimental showed a highly significant increase $(\mathrm{P}<0.0001)$ of DNA percentage in tail (fragmented DNA) of the comets in all three experimental groups. In terms of percentage there was an increase ie $4.13 \%, 6.94 \%$ and $14.31 \%$ of fragmented DNA in experimental groups $\mathrm{A}, \mathrm{B}$ and $\mathrm{C}$ respectively compared with control group (table 2).

Table 1. Mean percentage of motile, static, slow, moderate and rapid moving sperms in control and cryopreseved semen samples in extender A, B and

\begin{tabular}{|c|c|c|c|c|c|}
\hline Groups & Motile & Static & Slow & Moderate & Rapid \\
\hline Control & $78.33 \pm 0.81$ & $21.66 \pm 0.81$ & $11.19 \pm 0.71$ & $17.76 \pm 0.75$ & $48.96 \pm 0.77$ \\
\hline A & $72.50 \pm 0.59 \mathrm{a} * * *$ & $27.50 \pm 0.59 \mathrm{a} * * *$ & $10.60 \pm 0.36$ & $16.3 \pm 0.58$ & $45.76 \pm 0.40 \mathrm{a} * * *$ \\
\hline B & $67.20 \pm 0.53 \mathrm{a}, \mathrm{b}^{* * *}$ & $32.80 \pm 0.53 \mathrm{a}, \mathrm{b} * * *$ & $10.00 \pm 0.35$ & $15.83 \pm 0.38$ & $41.33 \pm 0.28 \mathrm{a}, \mathrm{b} * * *$ \\
\hline C & $60.10 \pm 0.43 \mathrm{a}, \mathrm{b}, \mathrm{c}^{* * *}$ & $39.90 \pm 0.43 \mathrm{a}, \mathrm{b}, \mathrm{c} * * *$ & $9.80 \pm 0.61 \mathrm{a} *$ & $17.06 \pm 0.33$ & $33.23 \pm 0.40 \mathrm{a}, \mathrm{b}, \mathrm{c} * * *$ \\
\hline
\end{tabular}

Values are expressed as Mean \pm SEM

$\mathrm{P}<0.5=*, \mathrm{P}<0.0001=* * *$

$\mathbf{a}=$ Control vs $\mathrm{A} \quad \mathbf{b}=\mathrm{A}$ vs $\mathrm{B}, \mathbf{c}=\mathrm{B}$ vs C

Table 2: Mean progressive velocity of sperms and Mean percentage head (intact) and tail (fragmented) DNA in control and cryopreseved semen in extender A, B and C.

\begin{tabular}{|c|c|c|c|}
\hline Groups & Progressive velocity $(\mu \mathrm{m} / \mathrm{sec})$ & \%DNA intact & \%DNA fragmented \\
\hline Control & $49.86 \pm 0.43$ & $82.35 \pm 0.20$ & $17.92 \pm 0.44$ \\
\hline A & $48.30 \pm 0.25 \mathrm{a}^{*}$ & $77.95 \pm 0.36 \mathrm{a}^{* * *}$ & $22.05 \pm 0.36 \mathrm{a} * * *$ \\
\hline B & $47.60 \pm 0.30 \mathrm{a} * * *$ & $75.14 \pm 0.54 \mathrm{a}, \mathrm{b} * * *$ & $24.86 \pm 0.54 \mathrm{a}, \mathrm{b}^{* * *}$ \\
\hline C & $44.46 \pm 0.38 \mathrm{a}, \mathrm{b}, \mathrm{c} * * *$ & $67.77 \pm 0.39 \mathrm{a}, \mathrm{b}, \mathrm{c} * * *$ & $32.23 \pm 0.39 \mathrm{a}, \mathrm{b}, \mathrm{c}^{* * *}$ \\
\hline
\end{tabular}

Values are expressed as Mean $\pm \operatorname{SEMP}<0.5=*, \mathrm{P}<0.0001=* * *$

Progressive velocity: $\mathbf{a}=$ Control vs $\mathrm{A}, \mathrm{B}, \mathrm{C} \mathbf{b}=\mathrm{A}$ vs $\mathrm{B}, \mathbf{c}=\mathrm{B}$ vs $\mathrm{C}$

\%DNA intact, \%DNA fragmented: $\mathbf{a}=$ Control vs $\mathrm{A}, \mathrm{B}, \mathrm{C} \mathbf{b}=\mathrm{A}$ vs $\mathrm{B}, \mathrm{C} \mathbf{c}=\mathrm{B}$ vs C 


\section{Discussion}

$\mathrm{AI}$ is a beneficial process and is world widely practiced yet the question which arose in our mind is of significant importance that the role of different CPAs as a part of most commonly used extender ie tris-egg yolk-citrate in the prevention of freezing damages be explored to the extent of semen quality deterioration and DNA damage level. Though the whole process of cryopreservation right from collection of semen to thawing and insemination cause varying degree of semen quality deterioration, the present study targeted the CPAs used in extenders keeping rest of the factors standardized. The present study provides persuasive support for the genotoxic effects of CPAs glycerol, DMSO and ethylene glycol as a part of tris-egg yolk-citrate extender during the cryopreservation process of Frisian bull semen. The study shows that glycerol, DMSO and ethylene glycol as a part of tris- egg yolk-citrate extender leads to significant sperm DNA damage and also significantly reduces the progressive velocity, percentage of rapidly moving sperms and percentage of motile sperms. The study shows that glycerol is the least toxic followed by DMSO and ethylene glycol.

Our results demonstrated that comets of fresh semen contained $17.92 \%$ damaged DNA however in cryopreserved it was $22.05 \%, 24.86 \%$ and $32.23 \%$ for glycerol, DMSO and ethylene glycol respectively. This is in contrast to an earlier study where $4-5 \%$ fragmentation of DNA was observed in cryopreserved semen of Holstein Frisian bulls using bioxcell (Mariola et al., 2008) indicating that extent of DNA damage also depends upon nature of extender used and breed of the animal. They also found $90 \%$ higher DNA disintegration as composite score after cryopreservation and results of present study suggest that apart from viability and motility, adequate echelons of DNA breakup after cryopreservation are typical feature of Frisian bull sperms. The findings of our study are indifference to an earlier finding where boar sperm DNA was characterized by above $100 \%$ increase in length of tail and tail moment (Fraser and Strzezek, 2007).

The comet assay reveals a mixture of preexistent single / double stranded breaks and alkali subtle sites which give rise to DNA breaks after DNA unwinding with alkaline treatment (Aravindan et al., 1997). It is not possible to assess the respective extend of these two phenomena with our method, but this amalgamation still provides a way to estimate DNA stability as discussed in study by Singh et al. (1989). It is unlikely that the break sites after the comet assay represent preexisting endogenous DNA damage since it is hard to envisage that sperm could tolerate high level of DNA damage and still produce high fertility rate. DNA damage can also be assessed by sperm chromatin structure assay (SCSA) and the Terminal Uridine Nick end-Labeling Assay (TUNEL).

The findings of present study were not compared with the results that could have been obtained through SCSA and TUNEL. Sperm DNA disintegration in human has been explored by the comet assay and was interrelated to the outcomes found with SCSA and TUNEL (Aravindan et al., 1997). Here the comet assay provided an appropriate image of the DNA stability after sperm irradiation. They detected a dose dependent rise of the broken nucleus percentage. Our study revealed sperm DNA fragmentation was more in cryopreserved semen and it may have resulted from a physical injury due to ice crystal formation, oxidative stress and as a result of free radicals emergence like reactive oxygen species (ROS). The efficiency of CPA depends upon its ability to replace the water and formation of hydrogen bonding with biological molecules so that freezing damages can be prevented therefore in the present study we can possibly infer that glycerol relatively caused high replacement of water molecules and contributed in reduction of freezing damages.

Careful sample preparation and adjustments of settings on the instrument greatly determines the validity of results obtained in CASA. To identify correctly moving sperm, static sperm, and particles (usually static) other than sperm (Anzar et al., 1991). In line to our study Hamilton Thorne equipment i.e., CEROS was used (Tardif et al., 1997) which permits the user to alter the settings easily, and gathering the results by visual inspection of the screen, the egg yolk, glycerol, Tris extender (EYGT) was chosen by them as we did because it is a successful extending medium for both liquid and frozen bull sperm and is the most widely used for freezing bull semen worldwide (Iritani, 1980). In contrast to our study they observed sperm velocity and the percentage of motile sperm were higher $(\mathrm{P}<0.05)$ after cooling than before cooling, which suggests that there was an adjustment or accommodation of the sperm cells to the media containing egg yolk during this cooling period. They suggested that velocity measurements might be more useful than the percentage of motile sperm in predicting the fertility of bull sperm stored in various media. The difference in their and our results is because they just cooled the semen at $5^{\circ} \mathrm{C}$ and we preserved it in liquid nitrogen. In line to present study in other animals there is almost a 50\%reduction in motile cells after cryopreservation (Watson, 1995). The efficiency of permeating (Adonitol, DMSO, Formamide, Glycerol, Propanediol) and non-permeating (Sucrose, Lactose, Trehalose, Raffinose, D Manitol) CPAs for cryoprotection of mouse sperms has been compared (Sztein et al., 2001). They demonstrated that among permeating the DMSO was found the best giving $42 \%$ motility. In our study we compared only permeating CPA and DMSO gave 67\% motility whereas the best result was obtained from glycerol with $72.5 \%$ motility. This suggests that cryopreserved bull semen is more resistant to deleterious effects than mouse.

Our results demonstrates that there is a direct correlation between semen quality deterioration (viability of sperms, motility, rapidly moving sperms, progressive velocity) and sperm DNA fragmentation during the act of 
cryopreservation with different CPAs which strengths our hypothesis. The increased number of static sperms with a corresponding increase in number of comets and fragmented percentage of sperm DNA in all three understudy CPAs is suggestive that the fragmentation of sperm DNA is also involving the nucleotide sequence of housekeeping genes responsible for sperm cell survival or at least the nucleotide sequence of the genes responsible for maintaining sperm cell motility. The compatibility of CPA with the extender used and type of semen required to be cryopreserved still require greater understanding however for cryopreservation of Frisian bull semen in tris-egg yolk-citrate extender, the glycerol as CPA is a better choice.

Foregoing in view of the present study we suggest that consequences of sperm cryopreservation on progeny development and the evaluation of progeny born out of AI be studied to explore the traits likely to be compromised during the act of fertilization with a damaged DNA sperm.

\section{Statement of Novelty}

Cryopreservation in dairy cattle has led us to produce best quality animals. The integrity of genetic material in sperm is important for its capability as well as for the transmission of genetic information from parents to offspring. The present study suggests that sperm DNA fragmentation results into sperm death as a result of breakages of housekeeping genes. Our data also suggest that glycerol as a cryoprotectant constituent of tris-egg yolk citrate extender offers a better protection for storage of cryopreserved Frisian bull semen in liquid nitrogen. This is novel finding which can help practitioners in improving cryoprotectants quality in the field of cryopreservation.

\section{Contribution of Each Author}

Dr Muhammad Amjad Khan conceived and designed the study and experiments. Dr Sarwat Jahan executed the laboratory procedures for Comet Assay, Ms Asmara Imtiaz executed laboratory procedures for semen analysis on CEROS. and analyzed the data statistically. The final version was approved after deliberate interpretation of data and critical revision for intellectual contents by all authors.

\section{REFERENCES}

[1] Albrecht AR, Cavia F, Larraburu M, et al., 2004. Heterospermic insemination at two sperm concentrations in timed AI and CASA semen parameters. Reprod 17:
$154-55$.

[2] Anderson D1and Laubenthal J, 2013. Analysis of DNA damage via single cell electrophoresis. Methods Mol Biol 1054:209-18.

[3] Anzar M, Hassan M, Graham ME, et al., 1991. Efficacy of the Hamilton Thorn Motility Analyzer (HTM-2030) for the evaluation of bovine semen. Theriogenol 36:307-9.

[4] Aravindan GR, Bjordahl LK and Jost J., 1997. Susceptibility of human sperm to in situ denaturation is strongly correlated with DNA strand breaks identified by single-cell electrophoresis. Cell Res 236:231-7.

[5] Bayejid M, Rakibul I, Firoza B, et al., 2015. Oxidative stress induced sperm DNA damage, a possible reason for male infertility. Iran J Reprod Med 13: 525-32.

[6] Correa JR, Heersche and Zavos PM, 1997. Sperm membrane functional integrity and response of frozen-thawed bovine spermatozoa during the hypoosmotic swelling test incubation at varying temperatures. Theriogenol 47: 715-21.

[7] Erma Z D and Martin J, 2015. The question of sperm DNA fragmentation testing in the male infertility work up. Reproductive Bio Medicine 31: 138-39.

[8] Estrada E, Rodríguez JE, Rocha LG, et al., 2014 Supplementing cryopreservation media with reduced glutathione increases fertility and prolificacy of sows inseminated with frozen-thawed boar semen Andrology 2(1):88-99.

[9] Fraser L and Strzezek J, 2007. Effect of different procedures of ejaculate collection, extenders and packages on DNA integrity of boar spermatozoa following freezing-thawing. Anim Reprod Sci 99: 317-29.

[10] Hammadeh ME, Askari A, Gerorg T, et al., 1999. Effect of freeze-thawing procedure on chromatin stability, morphological alteration and membrane integrity of human spermatozoa in fertile and subfertile men. Androlo 22: 155-62.

[11] Hammerstedt RH, Graham JK and Nolan JP, 1990. Cryopreservation of mammalian sperm what we ask them to survive. Androl 11: 73-88.

[12] Hinsch E, Hinsch KD, Boehm JG, et al., 1997. Functional parameteras and fertilization success of bovine semen cryopreserved in egg-yolk free and egg-yolk containing extenders. Reprod Dom Anim 321: 143- 49.

[13] Iritani A. 1980. Problems of freezing spermatozoa of different species. Proc. 9th Int. Congr. Animal. Reproduction -. Artificial Insemination. 10-11 February 1980 Madrid, Spain, pp 115.

[14] Karakaya E, Yilmazbas G, Keskin A, et al., 2014. Fertility in Dairy Cows after Artificial Insemination Using Sex-Sorted Sperm or Conventional Semen. Reprod Dom Anim 49: 333-7.

[15] Karlsson HL, Bucchianico S, Collins AR, et al., 2015. Can the comet assay be used reliably to detect nanoparticle-induced genotoxicity? Mol Mutagen 56(2): 82-96.

[16] Kousar S and Javed M, 2015. Diagnosis of metals induced 
DNA damage in fish using comet assay. Pak Vet $\mathrm{J}$ 35:168-72.

[17] Lemma A, 2010. Effect of cryopreservation on sperm quality and fertility. In: Artificial Insemination in Farm Animals (Manafi M, ed). INTECH Open Access Book Publisher, pp: 191-216.

[18] Mariola S, Halina K and C Andrzej. 2008. Comet assay of fresh and cryopreserved bull spermatozoa. Cryobiol 56: $100-2$

[19] Morris ID, Ilott S, Dixon L, et al., 2002. The spectrum of DNA damage in human sperm assessed by Comet assay and its relationship to fertilization and embryo development. Hum Reprod 17: 990-8.

[20] Naveen K, Goutam S, Carole C, et al., 2014. A 660-Kb Deletion with Antagonistic Effects on Fertility and Milk Production Segregates at High Frequency in Nordic Red Cattle: Additional Evidence for the Common Occurrence of Balancing Selection in Livestock. PLoS Genetics. 10: $1-9$.

[21] Neild D, Chaves G, Flores M, et al., 1999. Hypoosmotic test in equine spermatozoa. Theriogenol 51: 721-7.

[22] Phil V B and Peter N S, 2016. Sperm DNA damage and its role in IVF and ICSI. Basic Clin Androl 26: 15-23.

[23] Singh NP, McCoy MT, Tice RR, et al., 1989. A simple technique for quantification of low levels of DNA damage in individual cells. Exp Cell Res 175: 184-91.

[24] Soudabeh I, Francesca G, Eszter N, et al., 2016. The application of the comet assay to assess the genotoxicity of environmental pollutants in the nematode Caenorhabditis elegans. Environmental Toxicology and Pharmacology 45: $356-61$

[25] Steele EK, McClure N and Lewis SEM, 2000. Comparison of the effects of two methods of cryopreservation on testicular sperm DNA. Fertil Steril 74: 450-3.

[26] Swain JE and Smith GD, 2010. Cryoprotectants. In: Fertility cryopreservation (Chian RC and Quinn P). Cambridge University Press, New York, USA, pp 24-38.

[27] Sztein JM, Noble K, Farley JS, et al., 2001. Comparison of permeating and nonpermeating cryoprotectants for mouse sperm cryopreservation. Cryobiol 42: 28-39.

[28] Tardif AL, Farrell PB, Trend VT, et al., 1997. Computer assisted sperm analysis for assessing initial semen quality and changes during storage at $5^{\circ} \mathrm{C}$. Dairy Sci, 80: 1606-12.

[29] Thomas JM, Lock SL, Poock SE, et al., 2014. Delayed insemination of nonestrous cows improves pregnancy rates when using sex-sorted semen in timed artificial insemination of suckled beef cows. J Anim Sci 92: 1747-52.

[30] Watson PF, 1995. Recent developments and concepts in the cryopreservation of spermatozoa and the assessment of their post-thawing function. Reprod Fertil Dev 7: 871-91. 